\title{
Easy One-Pot Low-Temperature Synthesized Ag-ZnO Nanoparticles and Their Activity Against Clinical Isolates of Methicillin-Resistant Staphylococcus aureus
}

\author{
Atanu Naskart, Sohee Leet and Kwang-sun Kim* \\ Laboratory of RNA Biochemistry \& Superbacteria Research, Department of Chemistry and Chemistry Institute for Functional \\ Materials, Pusan National University, Busan, South Korea
}

\section{OPEN ACCESS}

Edited by:

Rafael Peña-Miller,

National Autonomous University

of Mexico, Mexico

Reviewed by:

Javier Alberto Garza Cervantes, Autonomous University of Nuevo

León, Mexico

Chin-Yuan Chang,

National Chiao Tung University,

Taiwan

*Correspondence:

Kwang-sun Kim

kwangsun.kim@pusan.ac.kr

${ }^{\dagger}$ These authors have contributed equally to this work

Specialty section:

This article was submitted to Synthetic Biology,

a section of the journal

Frontiers in Bioengineering and

Biotechnology

Received: 23 January 2020 Accepted: 03 March 2020

Published: 19 March 2020

Citation:

Naskar A, Lee S and Kim K (2020) Easy One-Pot Low-Temperature Synthesized Ag-ZnO Nanoparticles and Their Activity Against Clinical Isolates of Methicillin-Resistant

Staphylococcus aureus.

Front. Bioeng. Biotechnol. 8:216. doi: 10.3389/fbioe.2020.00216
Antimicrobial resistance (AMR) is widely acknowledged as a global health problem, yet the available solutions to this problem are limited. Nanomaterials can be used as potential nanoweapons to fight against this problem. In this study, we report an easy one-pot low-temperature synthesis of Ag-ZnO nanoparticles (AZO NPs) and their targeted antibacterial activity against methicillin-resistant Staphylococcus aureus (MRSA) strains. The physical properties of the samples were characterized by X-ray diffractometry $(X R D)$, transmission electron microscopy (TEM), and $X$-ray photoelectron spectroscopy (XPS). Furthermore, minimum inhibitory concentration (MIC), zone of inhibition (ZOI), and scanning electron microscopy (SEM) images for morphological characterization of bacteria were assessed to evaluate the antibacterial activity of AZO NPs against both Gram-negative [Escherichia coli (E. coli) and Acinetobacter baumannii (A. baumannii) standard and AMR strains] and Gram-positive (S. aureus, MRSA3, and MRSA6) bacteria. The AZO NPs showed comparatively better antibacterial activity against $S$. aureus and MRSA strains than Gram-negative bacterial strains. This costeffective and simple synthesis strategy can be used for the development of other metal oxide nanoparticles, and the synthesized nanomaterials can be potentially used to fight against MRSA.

Keywords: low-temperature solution synthesis, Ag-ZnO nanoparticles, antibacterial activity, Gram-positive bacteria, MRSA

\section{INTRODUCTION}

Antimicrobial resistance (AMR) is the ability of a given microbe to resist the effects of multiple antibiotics (Huijbers et al., 2015; Prestinaci et al., 2015). AMR is easily recognized in hard-to-treat pathogens and has become an alarming issue complicating health care and many other sectors (Eliopoulos et al., 2003; Jasovsky et al., 2016). For instance, methicillin-resistant Staphylococcus aureus (MRSA) is one of the most well-known AMR bacterial species for which immediate intervention is necessary, but even the long considered last-resort antibiotic vancomycin cannot be used in the treatment of MRSA infections since vancomycin-resistant $S$. aureus (VRSA) strains 
have emerged (Naskar and Kim, 2019; Naskar et al., 2020). In addition, AMR S. aureus species are one of 12 families of priority pathogenic bacteria listed by the World Health Organization (WHO) for which antibiotics are urgently needed (World Health Organization [WHO], 2017). Several new currently approved oxazolidinone class antibiotics, including Sivextro (Hall et al., 2018), tigecycline (Hall et al., 2018), and LCB01-0371 (Jeong et al., 2010) to eradicate $S$. aureus species resistant to last-resort antibiotics have been developed. However, it is possible that bacteria might continue to evolve to evade this new class of lastresort antibiotics, and it takes much time to find other alternatives and their mechanism of action in response to a newly generated resistant strain. Therefore, new alternatives to antibiotics are desperately needed for the fight against AMR pathogens.

In this present scenario, nanomaterials have emerged as both viable and versatile alternatives to current antibiotics to fight against AMR bacteria as it showed effectiveness in low dosages also where chances of bacteria getting resistance is also less (Regí et al., 2019). The main advantage of nanoparticles as antibacterial agents (i.e., nanoweapons) is that they function via a multiple target approach compared to the single target approach of antibiotics to inhibit the growth of bacteria (Naskar et al., 2016; Baptista et al., 2018). Therefore, it is harder for bacteria to attain resistance toward nanoparticles. A large surface area to volume ratio is also one of the major advantages of nanoparticles for their use in various biomedical applications including antibacterial activity (Navya and Daima, 2016; Naskar et al., 2018). Among such nanomaterials, metal- and metal oxide-based nanoparticles have been preferred by researchers to combat AMR bacterial cells (Wang et al., 2017). However, silver (Ag) nanoparticles (NPs) have been the most effective and promising antibacterial candidates since ancient times due to their inhibitory and antibacterial properties against microorganisms, including 16 major species of bacteria (Lee and Jun, 2019). Moreover, zinc oxide $(\mathrm{ZnO})$ NPs are another well-known antibacterial nanomaterial (Sirelkhatim et al., 2015; Hassan et al., 2017; Kumar et al., 2017; Naskar et al., 2017). ZnO nanoparticles have been recognized as a safe material by the US Food and Drug Administration [(21CFR182.8991) (Food and Drug Administration (FDA), 2015)]. Therefore, Ag-ZnO (AZO) NPs can be a potential alternative to conventional antibiotics in the fight against AMR bacteria.

Several methods like sol-gel (Lu et al., 2011) hydrothermal (Zhang and Mu, 2007) co-precipitation (Md Subhan et al., 2014), and plasma-assisted chemical vapor deposition (Simon et al., 2011) have been successfully reported for the synthesis of AZO NPs. However, all of these processes use high temperature and high pressure with long reaction times and multiple steps, which limit the use of AZO NPs in various applications (Matai et al., 2014). Very few reports, in fact, are available regarding the single step and low temperature synthesis of AZO NPs for the killing of AMR pathogens (especially MRSA pathogens) despite the immense potential for AZO NPs as antibacterial agents.

In the present work, a simple one-pot low-temperature synthesis method was developed to successfully synthesize AZO NPs from simple metal precursors and hydrazine hydrate.
The antibacterial activity of the synthesized nanoparticles was evaluated for AMR strains of Gram-positive bacteria, including MRSA strains, and Gram-negative bacteria.

\section{MATERIALS AND METHODS}

\section{Synthesis of $\mathrm{ZnO}(\mathrm{ZO})$ and $\mathrm{Ag}-\mathrm{ZnO}$ (AZO) NPs}

Initially, a fixed quantity ( $1 \mathrm{~g}$ ) of zinc nitrate hexahydrate $\left(\mathrm{Zn}\left[\mathrm{NO}_{3}\right]_{2} \cdot 6 \mathrm{H}_{2} \mathrm{O}\right.$, Merck) and requisite amount of silver nitrate $\left(\mathrm{AgNO}_{3}, \mathrm{ACS}, \geq 99.9 \%\right.$ ) [0 and 5 atomic percent (at\%) with respect to $\mathrm{Zn}$ ] was uniformly dispersed in $50 \mathrm{~mL}$ of deionized water (DW) with continuous stirring for $60 \mathrm{~min}$ at room temperature. In the next step, $1 \mathrm{~mL}$ of hydrazine hydrate $\left(\mathrm{N}_{2} \mathrm{H}_{4} \cdot \mathrm{H}_{2} \mathrm{O}\right.$, Merck, 99-100\%) was added dropwise to the reaction mixture with continuous stirring. Subsequently, the mixture was ultrasonicated for $10 \mathrm{~min}$ in a water bath ultrasonicator. Now, gray colored precipitation was clearly visible in the reaction beaker. The same steps, i.e., dropwise addition of hydrazine hydrate and ultrasonication, were repeated until the $\mathrm{pH}$ of the medium reached eight. Afterward, the precipitate of solid materials was separated by centrifugation and DW and ethanol were used for washing. Finally, the samples were dried in an oven at $\sim 60^{\circ} \mathrm{C}$ for $24 \mathrm{~h}$. The products were designated as $\mathrm{ZO}$ and $\mathrm{AZO}$ where the at\% used in the precursors was 0 and 5 , respectively.

\section{Characterization}

\section{Material Properties}

$\mathrm{X}$-ray diffraction (XRD) using an X-ray diffractometer (D8 Advance with DAVINCI design XRD unit, Bruker) with nickel filtered $\mathrm{Cu} \mathrm{K} \alpha$ radiation source $(\lambda=1.5406 \AA)$ was used to evaluate the structures of $\mathrm{ZO}$ and $\mathrm{AZO}$. The diffraction patterns were collected in the $2 \theta$ range of $20-80^{\circ}$. Moreover, the microstructure of the representative sample of AZO was assessed by transmission electron microscopy (TEM; Bruker Nano $\mathrm{GmbH}$ ). Carbon coated 300 mesh $\mathrm{Cu}$ grids were used for placing the samples. An Axis Supra Scanning X-ray photoelectron spectroscopy (XPS) microprobe surface analysis system was used to assess a representative sample of AZO by scanning the binding energy ranging from 200 to $1,200 \mathrm{eV}$ to determine the chemical state of elements. The $\mathrm{C} 1 \mathrm{~s}$ peak position at $284.5 \mathrm{eV}$ was used as the binding energy reference.

\section{Growth of Bacteria for Evaluation of the Antibacterial Activity}

Generally, antibacterial activity was evaluated according to a previous report (Naskar et al., 2020) using BBL ${ }^{\mathrm{TM}}$ MuellerHinton Broth (MHB, Becton Dickinson) grown bacterial strains including E. coli (ATCC 25922), A. baumannii (ATCC 19606), S. aureus (ATCC 25923); AMR strains of E. coli (1368), A. baumannii (12001); and different MRSA clinical isolates (Shin et al., 2019). Briefly, the MHB medium was used for the inoculation of single colonies of bacteria, which were incubated at $37^{\circ} \mathrm{C}$ overnight, followed by dilution of the cells to an optical density of 0.5 McFarland turbidity standard 
using Sensititre ${ }^{\mathrm{TM}}$ Nephelometer (Thermo Scientific). The cell cultures were used within $30 \mathrm{~min}$ after dilution to prepare samples for minimum inhibitory concentration (MIC) assay (section "MIC for Evaluation of the Antibacterial Activity") or scanning electron microscopy (SEM) analysis (section "Morphological Characterization of Bacteria") to assess the antibacterial activity of NPs (ZO and AZO) and characterize cell morphology, respectively.

\section{MIC for Evaluation of the Antibacterial Activity}

All bacteria were incubated overnight in the MHB medium. The number of cells was determined with a Sensititre ${ }^{\mathrm{TM}}$ Nephelometer to a $0.5 \mathrm{McFarland}$ standard and diluted at a ratio of $1 / 1,000$ in $\mathrm{MHB}$. The $\mathrm{ZO}$ and $\mathrm{AZO}$ samples $(5 \mathrm{mg} / \mathrm{mL}$ each) were prepared by serial dilution with DW to obtain concentrations from 250 to $10 \mu \mathrm{g} / \mathrm{mL}$. Then, $90 \mu \mathrm{L}$ of the targeted bacterial medium was inoculated with $10 \mu \mathrm{L}$ of each diluted sample. The bacterial cells were incubated by shaking at $500 \mathrm{rpm}$ for $16 \mathrm{~h}$ at $37^{\circ} \mathrm{C}$. The MIC was evaluated after this process.

\section{Agar Well Diffusion Method for Evaluation of the Antibacterial Activity}

The antibacterial activity of $\mathrm{ZO}$ and $\mathrm{AZO}$ against the bacterial strains of E. coli, A. baumannii, S. aureus, MRSA3, and MRSA6 was further evaluated with the agar well diffusion method. First, $500 \mu \mathrm{L}$ of cultured bacterial cells were mixed with $25 \mathrm{~mL}$ of MHB-agar, poured into sterile petri dishes $(\phi=90 \mathrm{~mm})$, and solidified. Then, five holes, $6 \mathrm{~mm}$ in diameter each, were aseptically punched through the surface with a sterile plastic rod. Afterward, $20 \mu \mathrm{L}$ of $\mathrm{ZO}$ or AZO $(5 \mathrm{mg} / \mathrm{mL})$, polymyxin $\mathrm{B}$ or kanamycin (5 mg/mL, Sigma-Aldrich), or DW was added for the experimental group, the positive control for Gram-negative or -positive strains, and the negative control group respectively. The plates were then incubated for $24 \mathrm{~h}$ at $37^{\circ} \mathrm{C}$. Finally, the antibacterial activities were evaluated by measuring the diameter of the zone of inhibition (ZOI) around the wells using a ruler.

\section{Morphological Characterization of Bacteria}

At first, prepared bacterial cells through the same process as described in section "Growth of Bacteria for Evaluation of the Antibacterial Activity" were diluted at a ratio of $1 / 1,000$ in the MHB medium according to MIC assay. $900 \mu \mathrm{L}$ of prepared cells were incubated with $100 \mu \mathrm{L}$ of the three final concentration 0,10 , and $20 \mu \mathrm{g} / \mathrm{mL}$ of $\mathrm{AZO}$ for $16 \mathrm{~h}$ at $37^{\circ} \mathrm{C}$ with vigorous shaking. After that, the incubated cells were harvested by centrifugation at $12,000 \mathrm{rpm}$ for $1 \mathrm{~min}$ to get a pellet. Then this pellet was resuspended in $500 \mu \mathrm{L}$ of phosphate buffered solution $(\mathrm{pH}$ 7) containing $2 \%$ formaldehyde and $1 \%$ glutaraldehyde, and centrifuged again. Subsequently, the obtained cell pellet was washed twice with DW and resuspended in $1 \mathrm{~mL}$ of $\mathrm{DW}$ for further experimentation. A $5 \mu \mathrm{L}$ aliquot was taken from the suspension and deposited on a silicon wafer $(5 \mathrm{~mm} \times 5 \mathrm{~mm}$ in size, Namkang Hi-Tech Co., Ltd.) to dry at room temperature. Finally, the air-dried wafer was subjected to SEM analysis using VEGA3 (TESCAN), a versatile tungsten thermionic emission SEM system, according to the manufacturer's protocol.

\section{RESULTS AND DISCUSSION}

\section{Material Properties \\ Phase Structure}

XRD was used to analyze the crystalline phase of samples. Figure 1 shows the XRD patterns of as-synthesized $\mathrm{ZO}$ and AZO samples. The obtained XRD patterns of the samples were consistent with hexagonal $\mathrm{ZnO}$ (h-ZnO) (JCPDS 36-1451) (Saloga and Thünemann, 2019). Moreover, some additional peaks can be seen at $\sim 38.1^{\circ}, \sim 44.3^{\circ}, \sim 64.5^{\circ}$, and $\sim 77.4^{\circ}$ for AZO samples, which corresponded to the crystal planes of cubic Ag (JCPDS 04-0783) along (111), (200), (220), and (311), respectively (Nogueira et al., 2014). Therefore, the formation of AZO NPs was successfully confirmed.

\section{Morphology and Microstructure}

Transmission electron microscopy (TEM) was conducted systematically to further investigate the formation of $\mathrm{ZO} / \mathrm{AZO}$ nanoparticles. The TEM image of the AZO sample and the corresponding HRTEM and HAADF images are shown in Figures 2a-d, respectively. The HRTEM image (Figure 2c) of the AZO sample shows distinct lattice fringes with an interplanar distance of $0.28 \mathrm{~nm}$, corresponding to the (100) plane of hexagonal $\mathrm{ZnO}$ (Ren et al., 2016). This observation confirmed the presence of hexagonal $\mathrm{ZnO}$ in the AZO sample. Moreover, HRTEM showed lattice fringes having an interplanar distance of $0.23 \mathrm{~nm}$ (Figure 2c), which can be matched with (111) of Ag NP (Sareen et al., 2015). Therefore, the TEM characterization of the microstructure of the AZO sample confirmed the presence of both nanoparticles of $\mathrm{ZnO}$ and $\mathrm{Ag}$, which corroborated with the XRD result (Figure 1). Additionally, the TEM with energydispersive X-ray (TEM-EDX) spectral analysis of the AZO sample confirms the presence of $\mathrm{Zn}$ and $\mathrm{O}$ and corroborates that $\mathrm{ZnO}$ NPs were formed (Figure $\mathbf{2 b}$ ). The presence of Ag suggests the

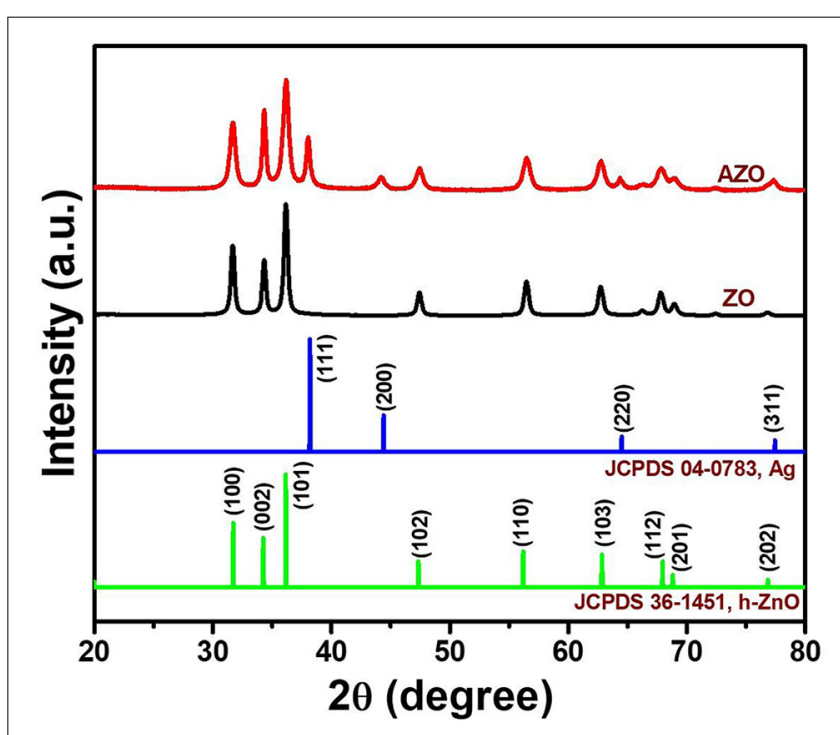

FIGURE 1 |XRD patterns of ZO and AZO samples. 

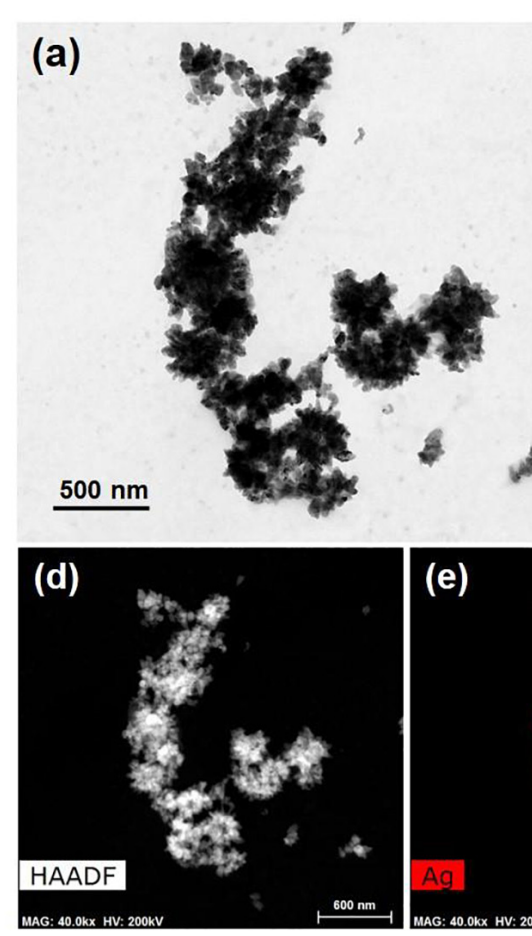
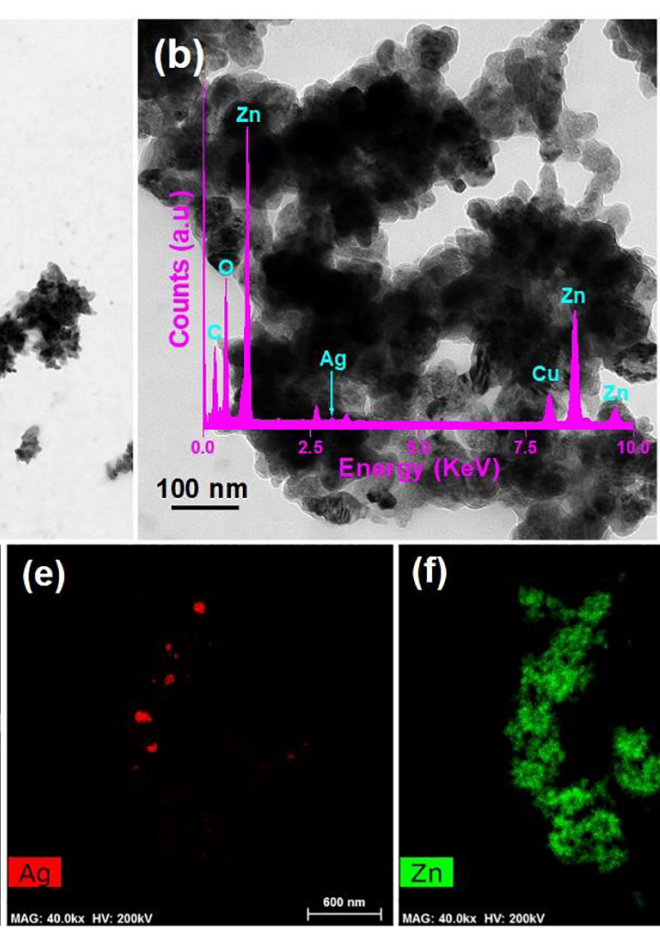

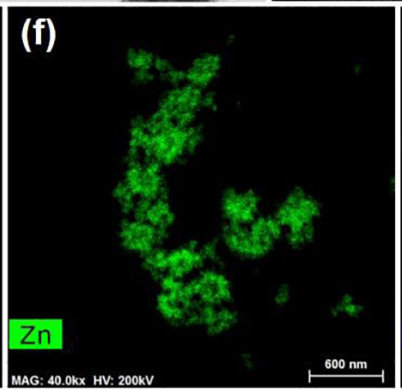

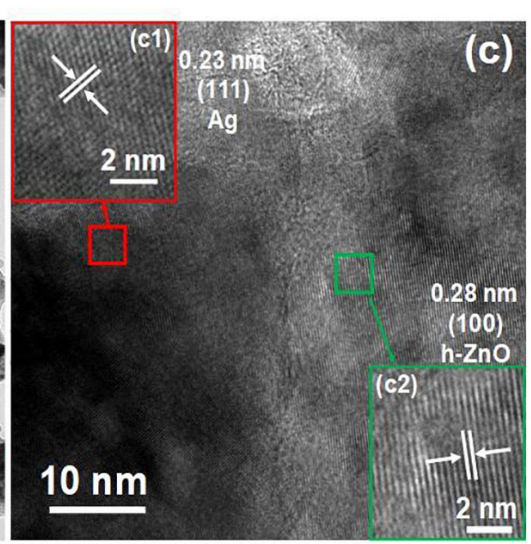

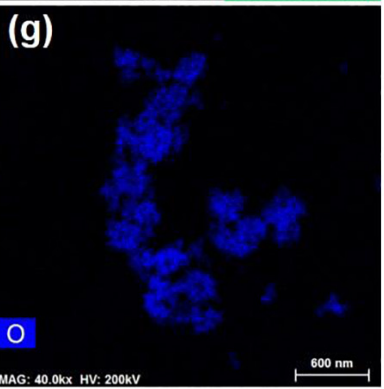

FIGURE 2 | TEM image (a,b) and HRTEM image (c) of AZO sample where (c1) and (c2) show the HRTEM images of the particles of Ag and ZnO, respectively with (b inset) TEM-EDS spectrum, (d) HAADF image, and elemental mappings of (e) Ag, (f) Zn, and (g) $\mathrm{O}$.
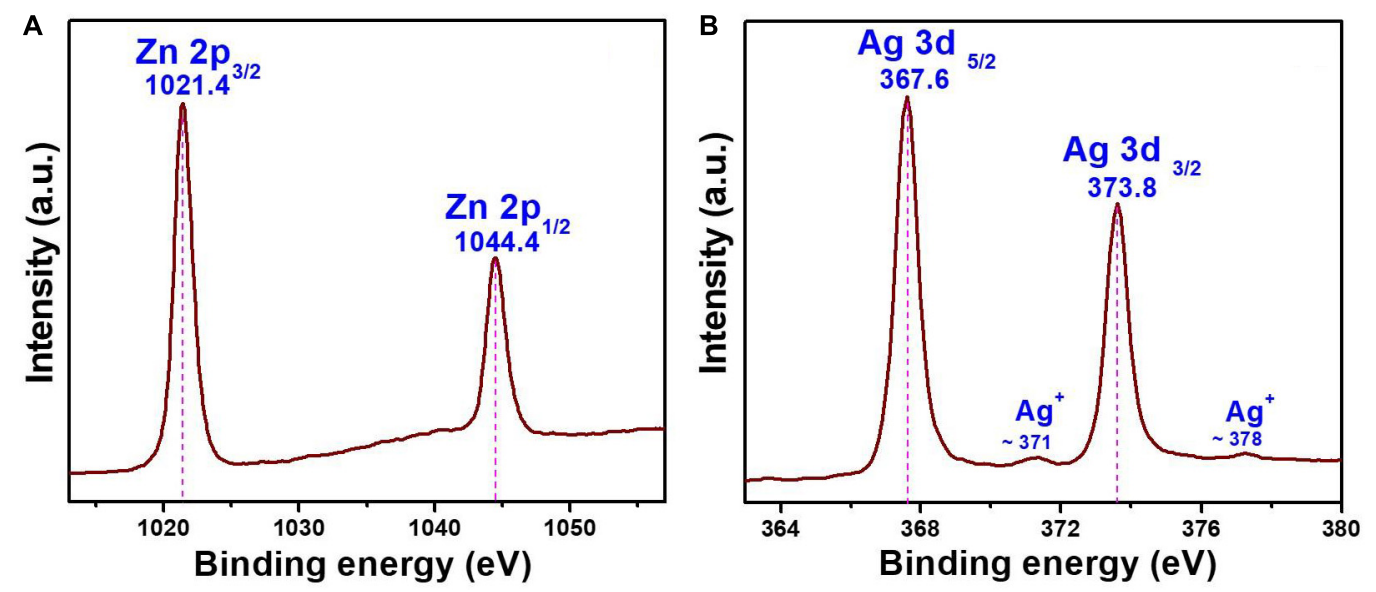

FIGURE 3 | XPS binding energy spectra of AZO (A) Zn 2p and (B) Ag 3d core levels.

formation of Ag NP in the Azo sample. The presence of $\mathrm{C}$ and $\mathrm{Cu}$ in the TEM-EDX spectrum can be attributed to the carbon coated $\mathrm{Cu}$ grid used for the TEM measurements. The elemental mapping result of $\mathrm{Ag}$ (Figure 2e), $\mathrm{Zn}$ (Figure 2f) and $\mathrm{O}$ (Figure 2g) for the representative $\mathrm{AZO}$ sample reveals the distribution $\mathrm{Ag}, \mathrm{Zn}$, and Au elements in the sample.

\section{XPS Spectra}

The oxidation state of the chemical elements present in the AZO sample was evaluated by XPS analysis, and the binding energy signals of the $\mathrm{Zn} 2 p$ and $\mathrm{Ag} 3 d$ core levels are shown in Figure 3. Two strong signals were observed in the binding energy signals of $\mathrm{Zn} 2 p$ at 1021.4 and $1044.4 \mathrm{eV}$ (Figure 3A), which can be assigned to the binding energies of $\mathrm{Zn} 2 p_{3 / 2}$ and $\mathrm{Zn} \mathrm{2} 2 p_{1 / 2}$, respectively (Jiamprasertboon et al., 2019). The presence of zinc as $\mathrm{Zn}^{2+}$ in the nanomaterial was also confirmed by the energy difference calculated between $\mathrm{Zn} 2 p_{3} / 2$ and $\mathrm{Zn} 2 p_{1 / 2}$ binding energy levels, which was $\sim 23.0 \mathrm{eV}$ (Jiamprasertboon et al., 2019). Furthermore, the formation of Ag nanoparticles was also evaluated by the binding energy signals 
TABLE 1 | Antibacterial activity of ZnO samples.

\begin{tabular}{lcc}
\hline Bacteria cells & \multicolumn{2}{c}{$\begin{array}{c}\text { Minimum inhibitory } \\
\text { concentration }(\boldsymbol{\mu} \mathbf{g} / \mathbf{m L})\end{array}$} \\
\cline { 2 - 3 } & (i) ZO & (ii) AZO \\
\hline Standard strains & & \\
(a) E. coli ATCC 25922 & 250 & 100 \\
(b) A. baumannii ATCC 19606 & $>250$ & 250 \\
(c) S. aureus ATCC 25923 & 50 & 25 \\
AMR strains & & 250 \\
(d) E. coli 1368 & $>250$ & 250 \\
(e) A. baumannii 12001 & $>250$ & 50 \\
(f) MRSA3 & 100 & 50 \\
(g) MRSA6 & 100 & \\
\hline
\end{tabular}

Minimum inhibitory concentration (MIC) of ZO and AZO samples against both Gram-negative and -positive bacteria cells including their AMR strains. Data shown here is one of the representative from $n=3$.

of Ag $3 d$ (Figure 3B). The binding energy signals (Figure 3B) appearing at 367.6 and $373.8 \mathrm{eV}$ in the XPS curve of the AZO sample can be assigned to $\mathrm{Ag} 3 d_{5 / 2}$ and $\mathrm{Ag} 3 d_{3 / 2}$, respectively (Nguyen et al., 2018). This observation confirmed the formation of Ag NPs in the AZO sample. Moreover, two low intensity signals can also be seen at $\sim 371$ and $\sim 378 \mathrm{eV}$. These low intensity peaks can be attributed to a trace amount of $\mathrm{Ag}^{+}$ions present in the sample (Naskar et al., 2016). Therefore, the presence of metallic silver and vey less $\mathrm{Ag}^{+}$ could be effectively used against bacterial cells for antibacterial activity. This material property is successfully correlated with the antibacterial activity of this sample in later section of antibacterial activity.

\section{Antibacterial Activity MIC and ZOI}

The MIC values (Table 1) of the $\mathrm{ZO}$ and AZO samples were measured to evaluate the antibacterial effectiveness of the samples against standard strains of bacteria (E. coli [ATCC25922], A. baumannii [ATCC19606], and S. aureus [ATCC25923]) and AMR strains (E. coli 1368, A. baumannii 12001, MRSA3, and MRSA6). MIC determination clearly showed that the AZO sample was comparatively more effective against Gram-positive bacteria than Gram-negative bacteria. Although the AZO sample was effective against Gramnegative bacteria, its MIC was considerably very high against generic and AMR strains (100-250 $\mu \mathrm{g} / \mathrm{mL})$. However, the AZO sample was much more effective against Gram-positive bacterial cells; the MIC value for $S$. aureus and its AMR strains MRSA3 and MRSA6 were in the range of 25$50 \mu \mathrm{g} / \mathrm{mL}$.

In additional to the MIC determination, the agar well diffusion method was also used to further evaluate the antibacterial activity of AZO NPs. Initially, agar plates with bacterial cells were loaded with the synthesized NPs $(20 \mu \mathrm{L}$ at $5 \mathrm{mg} / \mathrm{mL})$ and incubated for $24 \mathrm{~h}$ at $37^{\circ} \mathrm{C}$. After that, the ZOI was measured. The bacterial growth inhibition capacity of the $\mathrm{ZO}$ and AZO samples

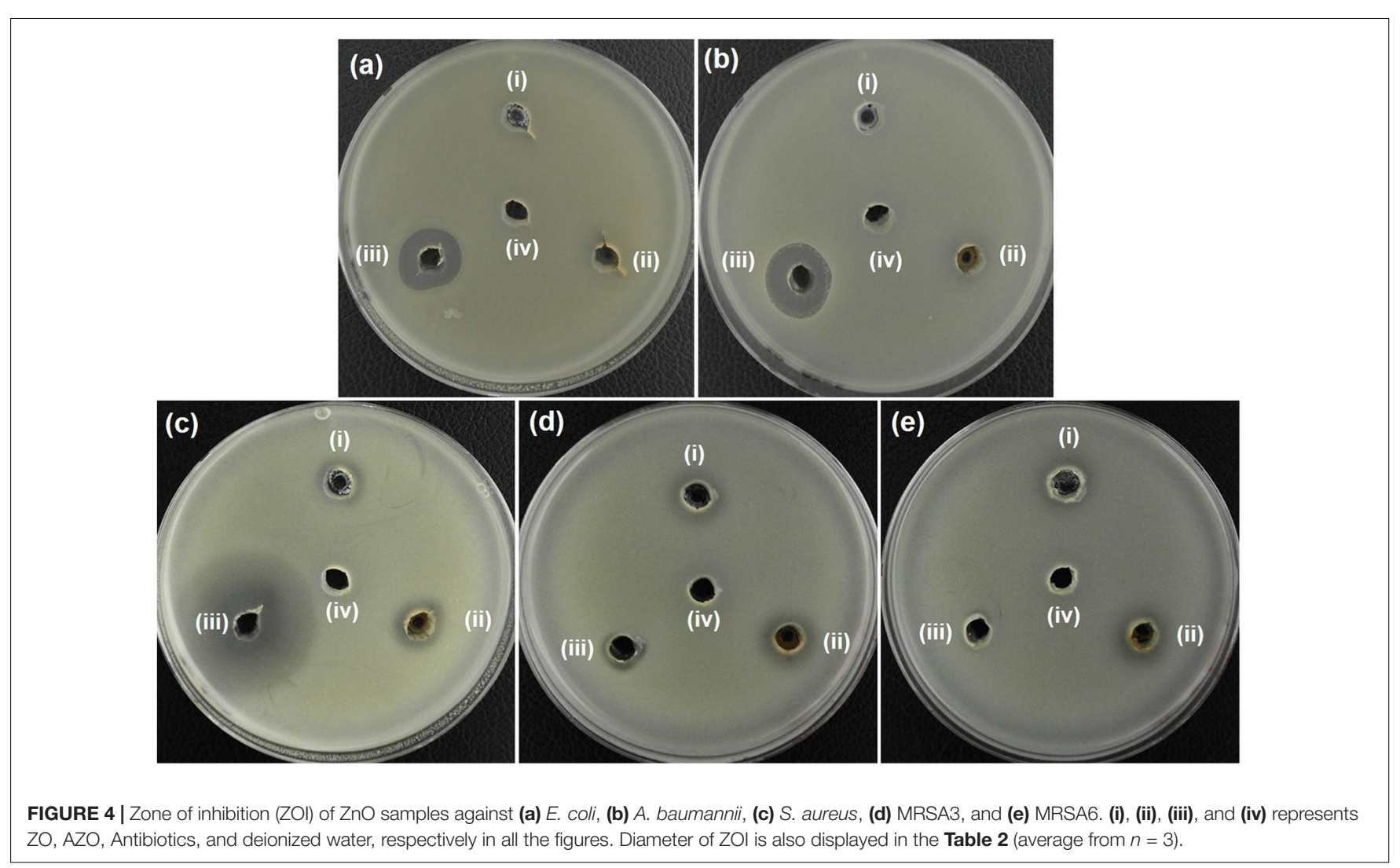


TABLE 2 | Zone of inhibition (ZOI) diameter of ZnO samples against (a) E. coli, (b) A. baumannii, (c) S. aureus, (d) MRSA3, and (e) MRSA6 was measured from $n=3$ and one of the representative data was shown.

\begin{tabular}{lcccc}
\hline Bacteria cells & \multicolumn{4}{c}{ Zone of inhibition (mm) } \\
\cline { 2 - 5 } & (i) ZO & (ii) AZO & (iii) Antibiotics & (iv) DW \\
\hline (a) E. coli ATCC 25922 & N.D. & N.D. & $17^{\mathrm{a}}$ & N.D. \\
(b) A. baumannii ATCC 19606 & N.D. & N.D. & $19^{\mathrm{a}}$ & N.D. \\
(c) S. aureus ATCC 25923 & 11 & 14 & $37^{\mathrm{b}}$ & N.D. \\
(d) MRSA3 & 11 & 14 & $12^{\mathrm{b}}$ & N.D. \\
(e) MRSA6 & 11 & 13 & N.D. & N.D.
\end{tabular}

N.D. indicates that the zone of inhibition was not detected. Antibiotics, a Polymyxin $B$ or ${ }^{b}$ Kanamycin was used as a control for Gram-negative or -positive bacteria, respectively. DW, deionized water. Data shown here is one of the representative from $n=3$.

against E. coli (Figure 4a), A. baumannii (Figure 4b), S. aureus (Figure 4c), MRSA3 (Figure 4d), and MRSA6 (Figure 4e) is provided in Table 2. The ZO and AZO NPs were unable to form an inhibition zone against Gram-negative bacterial cells of E. coli (Figure 4a) and A. baumannii (Figure 4b). These results support the MIC data (Table 1) for Gram-negative bacterial cells, from which it can be concluded that a more concentrated dispersion of AZO NPs would be necessary to obtain an inhibition zone i.e., to be effective against Gramnegative bacterial cells in the agar well diffusion antimicrobial determination. The ZOI against AMR strains (E. coli 1368, A. baumannii 12001) of Gram-negative bacterial cells was not determined, as it was assumed to be higher than the AZO sample, which was above the limit of detection for the concentration of AZO NPs used.

However, the AZO sample was effective in inhibiting the growth of Gram-positive bacterial cells including $S$. aureus (Figure 4c), MRSA3 (Figure 4d) and MRSA6 (Figure 4e). This observation corroborated the MIC determinations (Table 1). The effectiveness of the synthesized sample of AZO against the MRSA strains substantiates its potential to be used as a nanoweapon against AMR Gram-positive bacterial cells. Additionally, the MIC and ZOI data indicate that Grampositive bacteria are better targets for AZO NPs than Gramnegative bacteria.

\section{Morphological Characterization of Bacteria}

Given the antimicrobial efficacy of AZO NPs against Grampositive bacteria, the morphological features of standard and AMR strains of $S$. aureus (standard, MRSA3, and MRSA6) before and after exposure to AZO nanoparticles were evaluated by SEM. The SEM images of bacterial cells treated or untreated with AZO NPS is shown in Figure 5. In the untreated $S$. aureus cells, a smooth and intact surface was clearly visible (Figure 5a). On the other hand, some morphological changes such as membrane damage were seen in $S$. aureus treated with different concentrations of AZO (Figures 5b,c). Similar activity was seen in MRSA strains (MRSA3 and MRSA6) when comparing the untreated groups (Figures 5d,g), which both exhibited smooth surfaces, with the groups treated with different

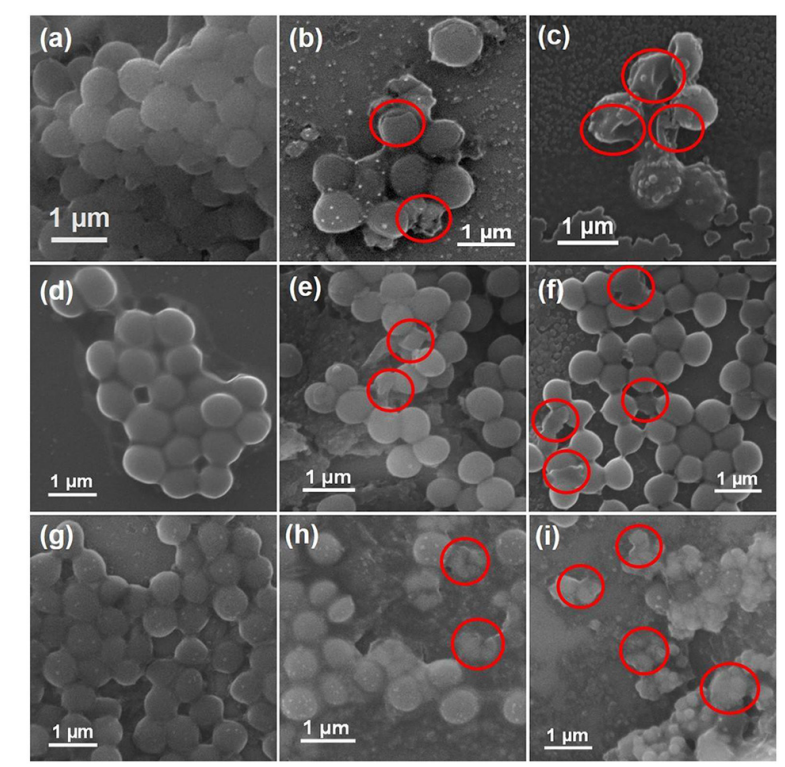

FIGURE 5 | Scanning electron microscopy (SEM) images of bacterial cells. Samples of S. aureus (a) untreated and treated with (b) $10 \mu \mathrm{g} / \mathrm{mL}$ and (c) $20 \mu \mathrm{g} / \mathrm{mL}$ of AZO. Samples of MRSA3 either (d) untreated or treated with (e) $10 \mu \mathrm{g} / \mathrm{mL}$ and (f) $20 \mu \mathrm{g} / \mathrm{mL}$ of AZO. Samples of MRSA6 either (g) untreated or treated with (h) $10 \mu \mathrm{g} / \mathrm{mL}$ and (i) $20 \mu \mathrm{g} / \mathrm{mL}$ of AZO. Red circles indicate areas of cell membrane disruption.

concentration of AZO NPs for MRSA3 (Figures 5e,f), and MRSA 6 (Figures 5h,i) which showed wrinkling and damage of the cell walls. Considerable damage was observed upon binding of the nanoparticle to the bacterial cell membrane (Figures 5e,f,h,i) to confirm the antibacterial effectiveness of AZO NPs. Therefore, the efficacy of AZO NPs against $S$. aureus and MRSA strains was successfully approved by the SEM micrographs.

It is well known that $\mathrm{Ag}$ and $\mathrm{ZnO} \mathrm{NPs}$ are established antibacterial agents; however, very little is known about their mechanism of antibacterial activity. In this study, we explored one possible mechanism of Ag and $\mathrm{ZnO} \mathrm{NP}$ antibacterial activity. It has been shown that some of the antibacterial activity of Ag and $\mathrm{ZnO}$ NPs may be attributed to a direct interaction between AZO NPs and the bacterial cell wall (Matai et al., 2014). The bacterial cell wall is generally negatively charged (Ghosh et al., 2012), which enables electrostatic interaction with the $\mathrm{Zn}^{2+}$ and $\mathrm{Ag}^{+}$ present in AZO NPs (which were identified in our ZO and AZO NPs by TEM analysis and XPS). Disruption of the bacterial cell membrane by Ag-ZnO NPs can be another potential mechanism for antibacterial activity (Naskar et al., 2020), which we have corroborated here using SEM. Membrane damage generally results in increased inhibition of DNA/plasmid replication by $\mathrm{Zn}^{2+} / \mathrm{Ag}^{+}$ions and the production of proteins/enzymes that affect bacterial cell functioning and contribute to cell death. Moreover, membrane disruption can also cause leakage of the intracellular material, which may shrink the cell and ultimately result in cell lysis (Yasir et al., 2019). 


\section{CONCLUSION}

In summary, we have developed a new strategy for the one-pot synthesis of $\mathrm{Ag}-\mathrm{ZnO}$ ( $\mathrm{AZO}$ ) nanoparticles using a low-temperature solution technique. The synthesized AZO sample showed admirable antibacterial activity against $S$. aureus bacteria including their AMR (MRSA) strains. Moreover, the antibacterial activity of the AZO sample was more specific toward Gram-positive bacteria than Gram-negative bacteria. This cost-effective simple synthesis strategy can be used as a platform to develop different metal oxide nanomaterials, which can be further used for targeted biomedical applications and may be useful as antibacterial agents to address the ever-increasing problem of AMR bacteria.

\section{DATA AVAILABILITY STATEMENT}

All datasets generated for this study are included in the article/supplementary material.

\section{REFERENCES}

Baptista, P. V., McCusker, M. P., Carvalho, A., Ferreira, D. A., Mohan, N. M., Martins, M., et al. (2018). Nano-strategies to fight multidrug resistant bacteria"A battle of the titans". Front. Microbiol. 9:1441.

Eliopoulos, G. M., Cosgrove, S. E., and Carmeli, Y. (2003). The impact of antimicrobial resistance on health and economic Outcomes. Clinical Infectious Diseases 36, 1433-1437. doi: 10.1086/375081

Food and Drug Administration (FDA) (2015). Select Committee on GRAS Substances (SCOGS) Opinion: Zinc Salts 2015. Washington, DC. Available online at: https://www.accessdata.fda.gov/scripts/cdrh/cfdocs/cfcfr/CFRSearch. cfm?fr=182.8991 (accessed March 9, 2020).

Ghosh, S., Goudar, V. S., Padmalekha, K. G., Bhat, S. V., Indi, S. S., and Vasan, H. N. (2012). ZnO/Ag nanohybrid: synthesis, characterization, synergistic antibacterial activity and its mechanism. RSC Adv. 2, 930-940. doi: 10.1039/ clra00815c

Hall, R. G., Smith, W. J., Putnam, W. C., and Pass, S. E. (2018). An evaluation of tedizolid for the treatment of MRSA infections. Expert Opin. Pharmacother. 19, 1489-1494. doi: 10.1080/14656566.2018.1519021

Hassan, I. A., Sathasivam, S., Nair, S. P., and Carmalt, C. J. (2017). Antimicrobial properties of copper-doped $\mathrm{ZnO}$ coatings under darkness and white light illumination. ACS Omega 2, 4556-4562. doi: 10.1021/acsomega.7b00759

Huijbers, P. M. C., Blaak, H., de Jong, M. C. M., Graat, E. A. M., VandenbrouckeGrauls, C. M. J. E., and de Husman, A. M. R. (2015). Role of the environment in the transmission of antimicrobial resistance to humans: a review. Environ. Sci. Technol. 49, 11993-12004. doi: 10.1021/acs.est.5b02566

Jasovsky, D., Littmann, J., Zorzet, A., and Cars, O. (2016). Antimicrobial resistance-a threat to the world's sustainable development. Upsala J. Med. Sci. 121, 159-164. doi: 10.1080/03009734.2016.1195900

Jeong, J.-W., Jung, S.-J., Lee, H.-H., Kim, Y.-Z., Park, T.-K., Cho, Y.-L., et al. (2010). In vitro and in vivo activities of LCB01-0371, a new oxazolidinone. Antimicrob Agents Chemother. 54, 5359-5362. doi: 10.1128/AAC.00 723-10

Jiamprasertboon, A., Dixon, S. C., Sathasivam, S., Powell, M. J., Lu, Y., Siritanon, T., et al. (2019). Low-cost one-step fabrication of highly conductive $\mathrm{ZnO}: \mathrm{Cl}$ transparent thin films with tunable photocatalytic properties via aerosolassisted chemical vapor deposition. ACS Appl. Electron. Mater. 1, 1408-1417. doi: 10.1021/acsaelm.9b00190

Kumar, R., Umar, A., Kumar, G., and Nalwa, H. S. (2017). Antimicrobial properties of $\mathrm{ZnO}$ nanomaterials: a review. Ceram. Int. 43, 3940-3961. doi: 10.1016/j. ceramint.2016.12.062

\section{AUTHOR CONTRIBUTIONS}

AN, SL, and KK contributed conception and design of the study, and wrote the manuscript. AN and SL performed the experiments. KK supervised the study. All authors contributed to the manuscript revision, and read and approved the submitted version.

\section{FUNDING}

This work was supported by the National Research Foundation of Korea (NRF) funded by the Korean Government (MSIT) (grant number 2018R1D1A1B07040941).

\section{ACKNOWLEDGMENTS}

We would like to extend our sincere gratitude to Professor Hyun Deok Yoo at the Department of Chemistry, Pusan National University, for allowing us to use the X-ray diffractometer.

Lee, S. H., and Jun, B.-H. (2019). Silver nanoparticles: synthesis and application for nanomedicine. Int. J. Mol. Sci. 20:865. doi: 10.3390/ijms20040865

Lu, Y., Lin, Y., Wang, D., Wang, L., Xie, T., and Jiang, T. (2011). Surface charge transfer properties of high-performance Ag-decorated $\mathrm{ZnO}$ photocatalysts. J. Phys. D: Appl. Phys. 44:315502. doi: 10.1088/0022-3727/44/31/315502

Matai, I., Sachdev, A., Dubey, P., Kumar, S. U., Bhushan, B., and Gopinath, P. (2014). Antibacterial activity and mechanism of Ag- $\mathrm{ZnO}$ nanocomposite on S. aureus and GFP-expressing antibiotic resistant E. coli. Colloids Surf. B 115, 359-367. doi: 10.1016/j.colsurfb.2013.12.005

Md Subhan, A., Awal, M. R., Ahmed, T., and Younus, M. (2014). Photocatalytic and antibacterial activities of $\mathrm{Ag} / \mathrm{ZnO}$ nanocomposities fabricated by coprecipitation method, Acta Metall. Sin 27, 223-232. doi: 10.1007/s40195-0140038-2

Naskar, A., Bera, S., Bhattacharya, R., Saha, P., Roy, S. S., Sen, T., et al. (2016). Synthesis, characterization and antibacterial activity of $\mathrm{Ag}$ incorporated $\mathrm{ZnO}-$ graphene nanocomposites. RSC Adv. 6, 88751-88761. doi: 10.1039/c6ra $14808 \mathrm{e}$

Naskar, A., Khan, H., and Jana, S. (2017). Cobalt doped ZnO-graphene nanocomposite: synthesis, characterization and antibacterial activity of water borne bacteria. Adv. NanoBioM D. 1, 182-190.

Naskar, A., Khan, H., Sarkar, R., Kumar, S., Halder, D., and Jana, S. (2018). Antibiofilm activity and food packaging application of room temperature solution process based polyethylene glycol capped Ag-ZnO-graphene nanocomposite. Mater. Sci. Eng. C 91, 743-753. doi: 10.1016/j.msec.2018.06.009

Naskar, A., and Kim, K.-S. (2019). Nanomaterials as delivery vehicles and components of new strategies to combat bacterial infections: advantages and limitations. Microorganisms 7:356. doi: 10.3390/microorganisms7090356

Naskar, A., Lee, S., and Kim, K.-S. (2020). Antibacterial potential of Ni-doped zinc oxide nanostructure: comparatively more effective against gram-negative bacteria including multidrug resistant strains. RSC $A d v$. 10, 1232-1242. doi: $10.1039 / \mathrm{c} 9 \mathrm{ra09512h}$

Navya, P. N., and Daima, H. K. (2016). Rational engineering of physicochemical properties of nanomaterials for biomedical applications with nanotoxicological perspectives. Nano Convergence 3:1. doi: 10.1186/s40580-016-0064-z

Nguyen, L., Tao, P. P., Liu, H., Al-Hada, M., Amati, M., Sezen, H., et al. (2018). Studies of surface of metal nanoparticles in a flowing liquid with XPS. Chem. Commun. 54, 9981-9984. doi: 10.1039/c8cc03497d

Nogueira, A. L., Machado, R. A. F., de Souza, A. Z., Martinello, F., Franco, C. V., and Dutra, G. B. (2014). Synthesis and characterization of silver nanoparticles produced with a bifunctional stabilizing agent. Ind. Eng. Chem. Res. 53, 34263434. doi: 10.1021/ie4030903 
Prestinaci, F., Pezzotti, P., and Pantosti, A. (2015). Antimicrobial resistance: a global multifaceted phenomenon. Pathog Glob Health 109, 309-318. doi: 10. 1179/2047773215Y.0000000030

Regí, M. V., González, B., and Barba, I. I. (2019). Nanomaterials as promising alternative in the infection treatment. Int. J. Mol. Sci. 20:3806. doi: 10.3390/ ijms20153806

Ren, L., Chen, D., Hu, Z., Gao, Z., and Luo, Z. (2016). Facile fabrication and application of $\mathrm{SnO} 2-\mathrm{ZnO}$ nanocomposites: insight into chain-like frameworks, heterojunctions and quantum dots. RSC Adv. 6, 82096-82102. doi: 10.1039/ c6ra19004a

Saloga, P. E. J., and Thünemann, A. F. (2019). Microwave-assisted synthesis of ultrasmall zinc oxide nanoparticles. Langmuir 35, 12469-12482. doi: 10.1021/ acs.langmuir.9b01921

Sareen, S., Mutreja, V., Singh, S., and Pal, B. (2015). Highly dispersed Au, Ag and $\mathrm{Cu}$ nanoparticles in mesoporous SBA-15 for highly selective catalytic reduction of nitroaromatics. RSC $A d v$. 5, 184-190. doi: 10.1039/c4ra10 $050 \mathrm{f}$

Shin, J., Magar, K. B. S., Lee, J., Kim, K.-S., and Lee, Y. R. (2019). Design, synthesis, and discovery of novel oxindoles bearing 3-heterocycles as species-specific and combinatorial agents in eradicating Staphylococcus species. Sci. Rep. 9:8012. doi: 10.1038/s41598-019-44304-1

Simon, Q., Barreca, D., Bekermann, D., Gasparotto, A., Maccato, C., and Comini, E. (2011). Plasma-assisted synthesis of $\mathrm{Ag} / \mathrm{ZnO}$ nanocomposites: first example of photo-induced $\mathrm{H} 2$ production and sensing. Int.J. Hydrogen Energy 36, 15527-15537. doi: 10.1016/j.ijhydene.2011. 09.045

Sirelkhatim, A., Mahmud, S., Seeni, A., Kaus, N. H. M., and Ann, L. C. (2015). Review on zinc oxide nanoparticles: antibacterial activity and toxicity mechanism. Nano Micro Lett. 7, 219-242. doi: 10.1007/s40820-0150040-x

Wang, L., Hu, C., and Shao, L. (2017). The antimicrobial activity of nanoparticles: present situation and prospects for the future. Int. J. Nanomed. 12, 1227-1249. doi: $10.2147 /$ IJN.S121956

World Health Organization, [WHO], (2017). Publishes list of bacteria for which new antibiotics are urgently needed. Available online at: https://www.who. int/news-room/detail/27-02-2017-who-publishes-list-of-bacteria-for-whichnew-antibiotics-are-urgently-needed (accessed on 13 January 2019).

Yasir, M., Dutta, D., and Willcox, M. D. P. (2019). Mode of action of the antimicrobial peptide Mel4 is independent of Staphylococcus aureus cell membrane permeability. PLoS One 14:e0215703. doi: 10.1371/journal.pone. 0215703

Zhang, Y., and Mu, J. (2007). One-pot synthesis, photoluminescence, and photocatalysis of Ag/ZnO composites J. Colloid Interface Sci. 309, 478-484. doi: $10.1016 /$ j.jcis.2007.01.011

Conflict of Interest: The authors declare that the research was conducted in the absence of any commercial or financial relationships that could be construed as a potential conflict of interest.

Copyright (c) 2020 Naskar, Lee and Kim. This is an open-access article distributed under the terms of the Creative Commons Attribution License (CC BY). The use, distribution or reproduction in other forums is permitted, provided the original author(s) and the copyright owner(s) are credited and that the original publication in this journal is cited, in accordance with accepted academic practice. No use, distribution or reproduction is permitted which does not comply with these terms. 